\title{
Atividade antimicrobiana de extratos hidroalcoolicos das folhas de alecrim- pimenta, aroeira, barbatimão, erva baleeira e do farelo da casca de pequi
}

\author{
Antimicrobial activity of hydroalcoholic extracts from rosemary, peppertree, barbatimão and erva \\ baleeira leaves and from pequi peel meal
}

\author{
Lucinéia de Pinho $^{\mathrm{I}^{*}}$ Patrícia Nery Silva Souza $^{\mathrm{I}}$ Eliane Macedo Sobrinho ${ }^{\mathrm{II}}$ \\ Anna Christina de Almeida ${ }^{\mathrm{I}}$ Ernane Ronie Martins $^{\mathrm{I}}$
}

RESUMO

Avaliou-se o perfil fitoquímico de extratos hidroalcoólicos padrão (EAPs), obtidos a partir das folhas de alecrim-pimenta (Lippia sidoides), aroeira (Myracrodruon urundeuva), barbatimão (Stryphnodendron adstringens), erva baleeira (Cordia verbenacea) e do farelo da casca do fruto do pequi (Caryocar brasiliense) e a atividade antimicrobiana de diferentes concentrações desses EAPs contra Staphylococcus aureus e Escherichia coli. Após coleta e identificação, as folhas das plantas e cascas do pequi foram usadas para preparação dos EAPs e submetidas a rastreamento fitoquímico. A atividade antimicrobiana dos EAPs em diferentes diluições (200, 300, 400 e 500 $\mathrm{m} \mathrm{mL}^{-1}$ ) foi testada pela técnica de difusão em ágar. $O$ rastreamento fitoquímico detectou componentes com potencial antimicrobiano em todos os EAPs. Nos testes de difusão em ágar, os extratos de aroeira ( $\left.\geq 200 \mathrm{mg} \mathrm{mL}^{-1}\right)$, barbatimão ( $\left.\geq 300 \mathrm{mg} \mathrm{mL}^{-1}\right)$ e erva-baleeira $\left(\geq 400 \mathrm{mg} \mathrm{mL}^{-1}\right)$ inibiram o crescimento de $\boldsymbol{S}$. aureus, mas não de $\boldsymbol{E}$. coli. Os EAPs não mostraram atividade sobre E.coli, todavia as folhas de aroeira, barbatimão e erva-baleeira evidenciaram potencial para inibir o crescimento de $\boldsymbol{S}$. aureus. $O$ uso das folhas $e$ cascas dessas espécies vegetais pode constituir-se numa alternativa sustentável, viável e acessível para tratamento antimicrobiano.

Palavras-chave: fitoterapia, extratos alcoolicos, susceptibilidade microbiológica.

\section{ABSTRACT}

This study evaluated the phytochemical profile of standardized hydroalcoholic extracts (EAPs) obtained from leafs of rosemary (Lippia sidoides), peppertree (Myracrodruon urundeuva), barbatimão (Stryphnodendron adstringens), erva

\begin{abstract}
baleeira (Cordia verbenacea) and from the meal of pequi fruit peel (Caryocar brasiliense) and the activity of different levels of these EAPs against Staphylococcus aureus and Escherichia coli. After collection and identification of the species, plant leaves and pequi peel were separated to prepare the EAPs. The EAPs underwent phytochemical screening. The antimicrobial activity of the EAPs at different dilutions (200, 300, 400 and $500 \mathrm{mg} \mathrm{mL}^{-1}$ ) was tested using the disk diffusion method. The phytochemical screening detected components with antimicrobial potential in the EAPs tested. The disk diffusion test showed that peppertree $\left(\geq 200 \mathrm{mg} \mathrm{mL}^{-1}\right)$, barbatimão ( $\geq 300 \mathrm{mg} \mathrm{mL}^{-1}$ ) and erva-baleeira ( $\geq 400 \mathrm{mg} \mathrm{mL}^{-1}$ ) extracts inhibited $\boldsymbol{S}$. aureus growth, but not $\boldsymbol{E}$. coli development. The EAPs did not affect $\boldsymbol{E}$. coli development, but the leaves from peppertree, barbatimão and erva-baleeira exhibited potential to inhibit $\boldsymbol{S}$. aureus growth. The leaves and bark of the studied plants may consist in a sustainable, affordable and feasible alternative to treat microbial infections.
\end{abstract}

Key words: phytoterapy, alcoholic extract, microbial susceptibility.

\section{INTRODUÇÃO}

Nas últimas décadas, foram intensificadas as investigações sobre fitoterápicos que possam oferecer tratamento alternativo de controle bacteriano (PUPO et al., 2007). O estudo desses agentes é importante no campo da saúde visto que se buscam, mundialmente, substâncias menos tóxicas e mais eficazes contra a resistência bacteriana e capazes de combater novos patógenos (BARBOSA-FILHO et al.,

Instituto de Ciências Agrárias, Universidade Federal de minas Gerais (UFMG), Montes Claros, MG, Brasil. *Endereço para correspondência: Av. Sidney Chaves, 1239, Bloco 08, apto 202, Bairro Edgar Pereira, 39400-648, Montes Claros, MG, Brasil. E-mail: lucineiapinho@hotmail.com.

"VALLÉE S.A., Montes Claros, MG, Brasil. 
2007; OSTROSKY et al., 2008). Com uma estrutura química que difere daquela dos antibióticos derivados de microrganismos, os antibióticos vegetais podem regular o metabolismo intermediário de patógenos, ativando ou bloqueando reações e síntese enzimática ou mesmo alterando a estrutura de membranas (MICHELIN et al., 2005). Além disso, os fitoterápicos têm baixo custo e podem ser usados conjuntamente à medicina alopática, além de seu uso ser inclusive incentivado pela Organização Mundial de Saúde (CAPASSO et al., 2003).

O uso de plantas medicinais é prática comum na medicina popular. Embora muitas pesquisas busquem isolar os componentes ativos dessas plantas, o efeito de um fitoterápico normalmente se dá pela ação sinérgica entre os compostos (MACIEL et al., 2002). Por isso, diferente de drogas convencionais, a medicina natural consiste em uma complexa preparação farmacêutica que pode ser administrada na forma de extrato (CAPASSO et al., 2003).

Sendo uma das mais ricas do planeta, a biodiversidade brasileira contém muitas plantas com propriedades antibióticas. Porém, essas espécies sofrem exploração irracional visto que grande parte dos fitoterápicos é retirada do caule e da raiz das plantas, o que pode ser uma séria ameaça às populações (MELO et al., 2008). A exploração sustentável de plantas medicinais incluiria medidas como a exploração de partes naturalmente renováveis como folhas e partes de frutos, que deveriam ser mais amplamente estudados.

No intuito de investigar o potencial fitoterápico de espécies da Mata Atlântica e Cerrado brasileiro e incentivar o uso renovável desses recursos, o presente estudo realizou o rastreamento fitoquímico de metabólitos secundários e testou o potencial antimicrobiano de extratos hidroalcoólicos obtidos de partes aéreas de plantas comuns da medicina popular brasileira. Assim, foram analisados os extratos de folhas de alecrim-pimenta (Lippia sidoides), aroeira (Myracrodruon urundeuva), barbatimão (Stryphnodendron adstringens), erva baleeira (Cordia verbenacea) e da casca do fruto de pequi (Caryocar brasiliense) e sua atividade antimicrobiana frente a Staphylococcus aureus (coco Gram positivo) e Escherichia coli (bacilo Gram negativo), ambos agentes de elevada prevalência na etiologia dos processos infecciosos bacterianos.

\section{MATERIAL E MÉTODOS}

Coleta e identificação dos vegetais

Folhas de alecrim-pimenta (Lippia sidoides), aroeira (Myracrodruon urundeuva), barbatimão (Stryphnodendron adstringens), erva baleeira (Cordia verbenacea) e casca do fruto de pequi (Caryocar brasiliense) foram coletadas no Instituto de Ciências Agrárias da Universidade Federal de Minas Gerais, Montes Claros, MG (latitude $16^{\circ} 40^{\prime} 50,92^{\prime \prime S ~ e ~}$ longitude $43^{\circ} 50^{\prime} 22,36^{\prime \prime} \mathrm{W}$; 646,29m de altitude). As coletas foram realizadas entre fevereiro e julho de 2008 , sempre no período da manhã, de acordo com a distribuição natural e disponibilidade das espécies. O material foi identificado por chaves de identificação, comparação com exsicatas dos herbários do ICA/UFMG e consulta a especialistas (LORENZI, 1998; ALMEIDA et al., 1998).

As folhas coletadas foram secas em estufa com circulação de ar a $40^{\circ} \mathrm{C}$ por $48 \mathrm{~h}$ e trituradas em moinho elétrico de facas. Também a casca do pequi foi separada, seca em estufa e moída. O pó de cada planta foi armazenado em recipiente escuro, hermeticamente fechado, até ser usado para produção dos extratos e rastreamento fitoquímico.

\section{Extratos hidroalcoolicos}

Os extratos hidroalcoolicos padrão (EAPs) foram obtidos segundo metodologia adaptada de KRYCHAK-FURTADO (2006). Os pós das plantas foram adicionados a etanol $50 \%$ e incubados em banhomaria a $60^{\circ} \mathrm{C}$ por 60 minutos. As suspensões foram filtradas quentes em funil com algodão e, para evaporação do solvente, levadas à estufa a $40^{\circ} \mathrm{C}$ até atingirem peso constante. $\mathrm{O}$ extrato bruto foi solubilizado em água destilada nas concentrações de 200, 300, 400 e $500 \mathrm{mg} \mathrm{mL}^{-1}$, as quais foram usadas nos ensaios para avaliação da atividade antimicrobiana.

\section{Rastreamento fitoquímico}

Os principais metabólitos secundários foram detectados de acordo com metodologia qualitativa proposta por MATOS (1997). Dessa forma, usou-se: A) teste de acidulação e alcalinização para detecção de antocianinas e catequinas; B) teste de fluorescência sob luz UV para cumarinas; C) reagente de LiebermanBurchard (anidrido acético + ácido sulfúrico concentrado) para esteroides e triterpenoides; D) cloreto férrico para fenóis simples e taninos, $\mathrm{Na}_{2} \mathrm{CO}_{3}$ para flavonas; E) reagente Shinoda ( $\mathrm{HCl}$ concentrado e fita de magnésio granulado) para flavonoides e xantonas; F) o teste de variação de $\mathrm{pH}$ (com hidróxido de sódio e ácido sulfúrico) para flavonois, flavanonas e flavanonois; e H) espuma com clorofórmio e água destilada para saponinas.

Atividade antimicrobiana dos extratos Preparação do inóculo

Foram utilizadas as cepas de Staphylococcus aureus ATCC 29213 (coco gram- 
positivo) e Escherichia coli ATCC 25753 (bacilo gram-negativo), previamente mantidos a $-20^{\circ} \mathrm{C}$. As amostras bacterianas foram recuperadas em ágar $\mathrm{BHI}$, incubadas a $37^{\circ} \mathrm{C}$ por $24 \mathrm{~h}$ e, a seguir, repicadas para caldo BHI até a fase logarítmica. Uma alíquota de $5 \mu \mathrm{L}$ de cada cultura (aproximadamente $10^{5} \mathrm{UFC} \mathrm{mL}^{-1}$ ) foi inoculada em placa de Petri com ágar BHI e incubada a $37^{\circ} \mathrm{C}$ por $24 \mathrm{~h}$. Os ensaios foram realizados em duplicatas.

Com uma alça bacteriológica, as culturas frescas desenvolvidas em ágar BHI foram inoculadas em tubos contendo caldo BHI e incubadas a $37^{\circ} \mathrm{C}$ por 24h. Após esse período, foram ressuspensas em solução salina estéril a $0,9 \%(\mathrm{p} / \mathrm{v})$ para se obter o inóculo padrão com uma turvação equivalente ao tubo 0,5 de McFarland, (aproximadamente 1,5x10 $\mathrm{UFC}$ $\left.\mathrm{mL}^{-1}\right)$. O inóculo padrão foi diluído em solução salina estéril $(0,9 \% \mathrm{p} / \mathrm{v})$ na proporção de $1: 100$.

Teste de difusão em ágar

$\mathrm{O}$ teste de difusão em ágar foi realizado segundo metodologia padrão de NCCLS (2002). Para tal, o inóculo microbiano padrão foi semeado na superfície de placa de ágar Muller-Hinton com swabs estéreis. Paralelamente, discos de papel de filtro $(6 \mathrm{~mm}$ diâmetro) esterilizados foram embebidos com $10 \mu \mathrm{L}$ dos EAPs de 200, 300, 400 ou $500 \mathrm{mg} \mathrm{mL}^{-1}$, iodo $10 \%$ (controle positivo) ou em água destilada estéril (controle negativo) com auxílio de micropipeta. Esses discos foram dispostos sobre a placa semeada com o inóculo com distância mínima de $24 \mathrm{~mm}$ entre eles (ORLANDO, 2005). A placa foi incubada a $37^{\circ} \mathrm{C}$ por $24 \mathrm{~h}$. A avaliação da atividade antimicrobiana foi realizada medindo-se os halos de inibição de crescimento bacteriano formados ao redor dos discos. Os ensaios foram feitos em triplicata.

\section{RESULTADOS E DISCUSSÃO}

O presente estudo demonstrou que os extratos alcoolicos obtidos das folhas das espécies avaliadas continham metabólitos secundários (Tabela 1) com potencial antimicrobiano e que os extratos de aroeira, barbatimão e erva-baleeira em especial conseguiram inibir o crescimento de $S$. aureus (Tabela 2). Apesar disso, não foi detectada atividade dos EAPs frente a $\boldsymbol{E}$. coli, o que pode estar relacionado à menor susceptibilidade das bactérias Gram-negativas a extratos vegetais.

De modo geral, as folhas têm menor concentração de agentes antimicrobianos que as cascas das plantas (VASCONCELOS et al., 2004). Porém, a elaboração de extratos a partir de folhas e frutas tem
Tabela 1 - Metabólitos secundários extraídos dos órgãos testados em cada planta.

\begin{tabular}{lccccc}
\hline Grupos & Alecrim & Aroeira* & Barbatimão* & Erva baleeira* & Pequi \\
\hline Antocianinas & - & - & - & - & - \\
Catequinas & + & - & - & - & + \\
Cumarina & - & - & - & - & - \\
Esteroides & + & + & + & - & + \\
Fenóis simples & + & + & + & - & + \\
Flavonas & - & + & - & + & + \\
Flavonoides & + & + & + & + & + \\
Flavonóis & + & + & - & - & + \\
Flavanonas & + & + & + & + & + \\
Flavanonóis & + & + & + & + & + \\
Saponinas & + & + & + & + & + \\
Taninos & + & + & + & + & + \\
Triterpenoides & - & - & - & + & - \\
Xantonas & + & + & - & + & + \\
\hline
\end{tabular}

${ }^{*}$ Corresponde às espécies de planta com atividade antimicrobiana detectada pelo teste de difusão em ágar.

a vantagem de ser uma prática sustentável que promove a sobrevivência da planta. Nesse sentido, o presente estudo mostrou através do rastreamento fitoquímico, que as espécies estudadas contêm metabólitos secundários importantes em suas folhas (e casca do fruto no caso do pequi) (Tabela 1). Nesses extratos, não foram detectadas antocianinas e cumarinas, porém todos possuíam flavonoides (flavanonas, flavanonóis), saponinas, taninos e taninos caquéticos, que possuem propriedades antimicrobianas. Outros estudos descrevem que flavonoides (flavonas, flavonóis e flavanonóis) (CUSHNIE, 2005) e saponinas (VERDI et al., 2005) têm atividade antimicrobiana importante. A ação antimicrobiana dos taninos é também conhecida (AKIYAMA et al., 2001), e já foi inclusive mostrado que extratos aquosos e acetônicos perdem a atividade frente a bactérias Gram-positivas quando eliminado seu conteúdo de tanino (DJIPA et al., 2000). É importante que em estudos futuros se compare o teor de metabólitos nas diferentes partes das plantas, especialmente da flora brasileira. Isso permitirá que novos produtos fitoquímicos sejam padronizados e usados em concentrações que garantam o efeito terapêutico.

Detectados os metabólitos, o teste de difusão em ágar indicou a atividade antimicrobiana dos extratos vegetais (Tabela 2). Nenhum dos extratos inibiu o crescimento de $\boldsymbol{E}$. coli, mas $\boldsymbol{S}$. aureus foi sensível aos extratos de barbatimão, aroeira e erva baleeira em concentrações que variaram de $200 \mathrm{mg} \mathrm{mL}^{-1}$ a $500 \mathrm{mg} \mathrm{mL}^{-1}$. Conforme os halos de inibição observados, a menor inibição foi alcançada pelo EAP de barbatimão 
Tabela 2 - Média (N=3) dos halos de inibição (mm) de crescimento bacteriano dos extratos vegetais contra S.aureus e E.coli.

\begin{tabular}{|c|c|c|c|c|c|c|c|}
\hline \multirow{2}{*}{ Cepa } & \multirow{2}{*}{ Espécie } & \multicolumn{4}{|c|}{--------------Extrato $\left(\mathrm{mg} \mathrm{mL}^{-1}\right)$-------------- } & \multirow{2}{*}{ Iodo $^{1}$} & \multirow{2}{*}{ Água $^{2}$} \\
\hline & & 200 & 300 & 400 & 500 & & \\
\hline \multirow{5}{*}{$\begin{array}{l}\text { S. aureus } \\
\text { ATCC29213 }\end{array}$} & alecrim-pimenta & - & - & - & - & 5 & - \\
\hline & aroeira & 1 & 2 & 3 & 3 & 8 & - \\
\hline & barbatimão & - & 1 & 1 & - & 7 & - \\
\hline & erva baleeira & - & - & 1 & 5 & 8 & - \\
\hline & pequi & - & - & - & - & 7 & - \\
\hline \multirow{5}{*}{$\begin{array}{l}\boldsymbol{E} . \text { coli } \\
\text { ATCC } 25753\end{array}$} & alecrim-pimenta & - & - & - & - & 2 & - \\
\hline & aroeira & - & - & - & - & 3 & - \\
\hline & barbatimão & - & - & - & - & 3 & - \\
\hline & erva baleeira & - & - & - & - & 3 & - \\
\hline & pequi & - & - & - & - & 3 & - \\
\hline
\end{tabular}

- = sem inibição do crescimento bacteriano

${ }^{1}$ controle positivo; ${ }^{2}$ controle negativo

e esse efeito não foi alterado com o aumento da dose de 300 para $500 \mathrm{mg} \mathrm{mL}^{-1}$. O EAP de aroeira evidenciou atividade bacteriostática crescente de 200 a $400 \mathrm{mg} \mathrm{mL}^{-1}$. Já o de erva-baleeira só apresentou atividade em concentrações acima de $400 \mathrm{mg} \mathrm{mL}^{-1}$, mas o halo de inibição produzido foi superior ao dos demais EAPs, atingindo $5 \mathrm{~mm}$.

Os EAPs obtidos das folhas de alecrimpimenta e da casca do fruto do pequi não mostraram atividade antimicrobiana embora isso tenha sido reportado em outros estudos. BARA \& VANETTI (1998) demonstraram que o extrato alcoólico de alecrimpimenta pode inibir completamente o crescimento de Salmonella thyphimurium, S. aureus, Listeria monocytogenes e Yersinia enterocolitica. Também os extratos etanólicos das folhas e cascas do pequi apresentam capacidade bactericida (PAULA-JUNIOR et al., 2006). A ausência de atividade antibacteriana no presente estudo pode ser decorrente da concentração do extrato, qualidade das folhas (alterada por condições de solo, sazonalidade, tipo de colheita e teor de ativos) ou mesmo da menor sensibilidade dos microorganismos estudados aos EAPs avaliados.

A casca da aroeira é usada como antiinfamatório e cicatrizante natural (CARMELLOGUERREIRO \& PAOLI, 1999) e, como mostrado nos testes microbiológicos apresentados, as folhas da aroeira também têm potencial terapêutico. Os resultados encontrados corroboram outros que encontraram atividade antimicrobiana de diferentes concentrações do extrato etanólico de folhas de aroeira contra bactérias Gram-positivas e Gram-negativas (MARTÍNEZ et al., 1996; SOARES et al., 2010).
A atividade antimicrobiana do barbatimão também foi confirmada contra S.aureus, mas não contra E. coli. AUDI et al. (2004) atribuíram o efeito antimicrobiano do extrato da casca de barbatimão ao seu alto teor de taninos. Outros estudos relatam a ação antimicrobiana de extratos de barbatimão (COWAN, 1999; QUEIROZ et al., 2002; CUNHA, 2006) e, na medicina popular, ele é usado no tratamento de úlceras, afecções vaginais e gonorreia, devido às suas propriedades cicatrizantes, anti-inflamatórias, hemostáticas, anti-sépticas, anti-diarreicas e antiedematogênicas (QUEIROZ et al., 2002). A maior parte dos trabalhos que confirmam a atividade antimicrobiana do barbatimão tem sido realizada com cascas e raízes (ORLANDO, 2005; SANTOS et al., 2007; NOGUEIRA et al., 2008), sendo que, no presente estudo, esta propriedade foi comprovada com as folhas da espécie.

Dentre os extratos avaliados, o maior efeito bacteriostático foi obtido para o EAP de erva-baleeira, particularmente frente a $\boldsymbol{S}$. aureus e em concentração acima de $400 \mathrm{mg} \mathrm{mL}^{-1}$. Isso está de acordo com outro estudo que mostrou a sensibilidade de bactérias Grampositivas e leveduras, bem como a resistência de bactérias Gram-negativas ao óleo essencial de ervabaleeira (CARVALHO, 2004). Comparando-se o perfil fitoterápico da erva-baleeira com o das demais espécies estudadas, observa-se que seu EAP foi o único que continha triterpenoides. Embora os triterpenoides fossem antes considerados metabólitos inócuos, estudos recentes mostram que eles desempenham ações fisiológicas importantes (SEIGLER, 2002). Assim, a ação isolada de triterpenoides e em combinação com outros metabólitos da erva-baleeira merecem 
investigação para se elucidar os processos fisiológicos envolvidos na resposta antimicrobiana detectada.

Os resultados apresentados são significativos, visto que as bactérias testadas estão entre os principais agentes causadores de infecções hospitalares no Brasil, conforme SADER et al. (2001). Nos resultados apresentados na tabela 2, ficou claro que E.coli ATCC 25753 foi menos sensível aos extratos testados que $\boldsymbol{S}$.aureus ATCC 29213. Esse resultado também foi encontrado por NOVAIS et al. (2003) que investigou extratos obtidos de outras espécies do semiárido brasileiro e corrobora a hipótese de que bactérias Gram-negativas (E. coli) são menos sensíveis a extratos vegetais que bactérias Gram-positivas (S. aureus) (PESSINI et al., 2003).

\section{CONCLUSÃO}

Os extratos hidroalcoólicos de folhas de aroeira, barbatimão e erva-baleeira apresentam atividade antibacteriana frente a $\boldsymbol{S}$. aureus, mas não frente a $\boldsymbol{E}$. coli. A inibição no crescimento de $\boldsymbol{S}$. aureus foi obtida com o EAP de aroeira acima de $400 \mathrm{mg} \mathrm{mL}^{-1}$, barbatimão a partir de $300 \mathrm{mg} \mathrm{mL}^{-1}$ e erva baleeira a partir de $500 \mathrm{mg} \mathrm{mL}^{-1}$. O uso das folhas e cascas dessas espécies vegetais pode constituir-se numa alternativa sustentável, viável e acessível para tratamento antimicrobiano.

\section{REFERÊNCIAS}

AKIYAMA, H. et al. Antibacterial action of several tannins against Staphylococcus aureus. Journal of Antimicrobial Chemotherapy, v.48, n.4, p.487-491, 2001. Disponível em: $<$ http://jac.oxfordjournals.org/content/48/4/487.long $>$. Acesso em: 14 out. 2011 . doi: 10.1093/jac/48.4.487.

ALMEIDA, S.P. et al. Cerrado: espécies vegetais úteis. Planaltina: Embrapa - CPAC, 1998. 464p.

AUDI, E.A. et al. Biological activity and quality control of extract and stem bark from Stryphnodendron adstringens. Acta Farmacéutica Bonaerense, v.23, n.3, p.328-333, 2004. Disponível em: <http://www.latamjpharm.org/trabajos/23/3/ LAJOP_23_3_1_9_2376GP9S8M.pdf>. Acesso em: 14 out. 2011. doi: $10.1002 /($ SICI)1099-1573(199905).

BARA, M.T.F.; VANETTI, M.C.D. Estudo da atividade antibacteriana de plantas medicinais, aromáticas e corantes naturais. Revista Brasileira de Farmacognosia, v.7-8, p.2134, 1998. Disponível em: <http://dx.doi.org/10.1590/S0102695X1998000100003>. Acesso em: 14 out. 2011. doi: 10.1590/S0102-695X1998000100003.

BARBOSA-FILHO, J.M. et al. Natural products with antileprotic activity. Revista Brasileira de Farmacognosia, v.17, p.141-148, 2007. Disponível em: <http://dx.doi.org/ 10.1590/S0102-695X2007000100022>. Acesso em: 14 out. 2011. doi: 10.1590/S0102-695X2007000100022.
CAPASSO, F. et al. Phytoterapy: a quick reference to herbal medicine. Berlin: Springer, 2003. 424p.

CARMELLO-GUERREIRO, S.M.; PAOLI, A.A.S. Morfologia e anatomia da semente de Schinus terebinthifolius Raddi (Anacardiaceae) em desenvolvimento. Revista Brasileira de Botânica, v.22, n.1, p.91-98, 1999. Disponível em: <http:/ /dx.doi.org/10.1590/S0100-84041999000100012>. Acesso em: 14 out. 2011. doi: 10.1590/S0100-84041999000100012.

CARVALHO JR, P.M et al. Chemical composition and antimicrobial activity of the essential oil of Cordia verbenacea D.C. Journal of Ethnopharmacology, v.95, n.2-3, p.297301, 2004. Disponível em: <http://www.sciencedirect.com/ science/article/pii/S037887410400409X>. Acesso em: 14 out. 2011. doi: $10.1016 /$ j.jep.2004.07.028.

CUNHA, L.S. Avaliação da atividade antimicrobiana de extratos brutos de plantas do cerrado, substâncias isoladas e derivados semi-sintéticos frente a microrganismos bucais. 2006. 170f. Dissertação (Mestrado em Ciências) - Curso de Pós-graduação em Ciências, Universidade de Franca, SP.

CUSHNIE T.P.; LAMB, A.J. Antimicrobial activity of flavonoids. International Journal of Antimicrobial Agents, v.26, p.343-356, 2005. Disponível em: <http:// download.journals.elsevierhealth.com/pdfs/journals/0924-8579/ PIIS0924857905002554.pdf>. Acesso em: 14 out. 2011. doi: 10.1016/j.ijantimicag.2005.09.00.

DJIPA, C.D. et al. Antimicrobial activity of bark extracts of Syzygium jambos (L) Alston (Myrtaceae). Journal of Ethnopharmacology, v.71, n.1-2, p.307-313, 2000. Disponível em: <http://www.farm.ucl.ac.be/Full-texts-FARM/ Djipa-2000.pdf $>$. Acesso em: 14 out. 2011. doi: 10.1016/ S0378-8741(99)00186-5.

KRYCHAK-FURTADO, S. Alternativas fitoterápicas para o controle da verminose ovina no estado do Paraná: testes in vitro e in vivo. 2006. 147f. Tese (Doutorado em Ciências) - Curso de Pós-graduação em Agronomia, Área de Produção Vegetal, Universidade Federal do Paraná, PR.

LORENZI, H. Árvores brasileiras: manual de identificação e cultivo de plantas arbóreas nativas do Brasil. Nova Odessa: Plantarum, 1998. 2v, 368p.

MACIEL, M.A.M. et al. Plantas medicinais: a necessidade de estudos multidisciplinares. Química Nova, v.25, n.3, p.429438, 2002. Disponível em: <http://www.scielo.br/ scielo.php? script=sci_arttext\&pid=S $0100-$

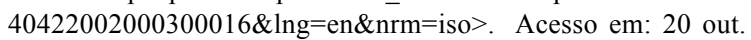
2011. doi: $10.1590 / \mathrm{S} 0100-40422002000300016$.

MARTÍNEZ, M.J. et al. Screening of some Cuban medicinal plants for antimicrobial activity. Journal of Ethnopharmacology, v.52, p.171-174, 1996. Disponível em: <http://www.sciencedirect.com/ science?_ob=MiamiImageURL\&_cid $=271283$ \&_user $=6864$ $13 \&$ pii $=0378874196014055 \&$ check $=y \&$ origin $=\&$ coverDate $=05$ J u $1-1996 \&$ vi e w $=\mathrm{c} \& \mathrm{w} \mathrm{c} \overline{\mathrm{h}} \mathrm{p}=\mathrm{d} \overline{\mathrm{G}} \mathrm{L} \mathrm{z}$ V $1 \mathrm{~B}-$ zSkzS\&md5=57d6e2ca21374d7759854a 8b72a9457b/1-s2.00378874196014055-main.pdf>. Acesso em: 14 out. 2011. doi: 10.1016/0378-8741(96)01405-5. 
MATOS, F.J.A. Introdução à fotoquímica experimental. 2.ed. Fortaleza: UFC, 1997. 141p.

MELO, J.G. et al. Native medicinal plants commercialized in Brazil - priorities for conservation. Environmental Monitoring and Assessment, v.156, n.1-4, p.567-580, 2008. Disponível em: <http://www.springerlink.com/content/ y78003r177g2516t/fulltext.pdf>. Acesso em: 14 out. 2011 doi: 10.1007/s10661-008-0506-0.

MICHELIN, D.C. et al. Avaliação da atividade antimicrobiana de extratos vegetais. Revista Brasileira de Farmacognosia, v.15, n.4, p.316-320, 2005. Disponível em: <http:// www.scielo.br/scielo.php? script=sci_arttext\&pid=S0102$695 X 2005000400010 \& \operatorname{lng}=\mathrm{en} \& \mathrm{nrm}=\mathrm{iso}>$. Acesso em: 14 out. 2011. doi: $10.1590 / \mathrm{S} 0102-695 \mathrm{X} 2005000400010$.

NCCLS, NATIONAL COMMITTEE FOR CLINICAL LABORATORY STANDARDS. Supplement table. Performance standards for antimicrobial disk susceptibility tests. Vilanova: NCCLS, 2002. 153p.

NOGUEIRA, J.C.R. et al. Atividade antimicrobiana in vitro de produtos vegetais em otite externa aguda. Revista Brasileira de Otorrinolaringologia, v.74, n.1, p.118-124, 2008. Disponível em: $<$ http://www.scielo.br/scielo.php?script=sci arttext\&pid=S0034$72992008000100019 \& \operatorname{lng}=$ en\&nrm=iso>. Acesso em: 14 out. 2011. doi: $10.1590 /$ S0034-72992008000100019.

NOVAIS, T.S. et al. Atividade antibacteriana em alguns extratos de vegetais do semi-árido brasileiro. Revista Brasileira de Farmacognosia, v.13, supl.2, p.5-7, 2003. Disponível em: $<\mathrm{http}: / /$ www.scielo.br/scielo.php?script=sci_arttext\&pid=S0102$695 \mathrm{X} 2003000400003 \& \operatorname{lng}=\mathrm{en} \& \mathrm{nrm}=\mathrm{iso}>$. Acesso em: 14 out 2011. doi: $10.1590 / \mathrm{S} 0102-695 \mathrm{X} 2003000400003$.

ORLANDO, S.C. Avaliação da atividade antibacteriana do extrato hidro-alcoólico bruto da casca do Stryphnodenfron adstringens (Martius) Coville (Barbatimão). 2005. 88f. Dissertação (Mestrado em Promoção da Saúde) - Curso de Pós-graduação em Promoção da Saúde, Universidade de Franca, SP. Disponível em: <http:/ dx.doi.org/10.1590/S0102-695X2003000400003>. Acesso em 14 out 2011 . doi: 10.1590/S0102-695X2003000400003.

OSTROSKY, E.A. et al. Métodos para avaliação da atividade antimicrobiana e determinação da concentração mínima inibitória (CMI) de plantas medicinais. Revista Brasileira de Farmacognosia, v.18, n.2, p.301-307, 2008. Disponível em: $<\mathrm{http} / / /$ dx.doi.org/10.1590/S0102-695X2008000200026>. Acesso em: 14 out. 2011. doi: 10.1590/S0102$695 \times 2008000200026$

PAULA-JUNIOR, W. et al. Leishmanicidal, antibacterial, and antioxidant activities of Caryocar brasiliensis leaves hydroethanolic extract. Revista Brasileira de Farmacognosia v.16, supl., p.625-30, 2006. Disponível em: $<$ http://dx.doi.org/10.1590/S0102-695X2006000500007>. Acesso em: 14 out. 2011. doi: 10.1590/S0102$695 \times 2006000500007$.
PESSINI, G.L. et al. Avaliação da atividade antibacteriana e antifúngica de extratos de plantas utilizados na medicina popular. Revista Brasileira de Farmacognosia, v.13, supl., p.21-24, 2003. Disponível em: $<\mathrm{http}: / / \mathrm{dx}$.doi.org/10.1590/S0102695X2003000300009>. Acesso em: 14 out. 2011. doi: 10.1590/S0102-695X2003000300009.

PUPO, M.T. et al. Biologia química: uma estratégia moderna para a pesquisa em produtos naturais. Química Nova, v.30, n.6, p. 1446-1455, 2007. Disponível em: <http://www.scielo.br/ scielo.php? script=sci_arttext\&pid=S 0100 $40422007000600014 \& \operatorname{lng}=\mathrm{en} \& n r m=i s o>$. Acesso em: 14 out. 2011. doi: $10.1590 / \mathrm{S} 0100-40422007000600014$

QUEIROZ, C.R.A.A. et al. Caracterização dos taninos da aroeira preta (Myracrodruon urundeuva). Revista da Árvore, v.26, p.493-497, 2002. Disponível em: <http://dx.doi.org/10.1590/ S0100-67622002000400011>. Acesso em: 14 out. 2011. doi: 10.1590/S0100-67622002000400011.

SADER, H.S. et al. Pathogen frequency and resistence patterns in Brazilian Hospitals: Summary of results from three years of the SENTRY antibacterial surveillance program. Brazilian Journal of Infectious Diseases, v.5, n.4, p.200-214, 2001. Disponível em: <http://dx.doi.org/10.1590/S141386702001000400006>. Acesso em: 14 out. 2011. doi: 10.1590/S1413-86702001000400006.

SANTOS, S.C. et al. Atividade antimicrobiana in vitro do extrato de Abarema cochliocarpos (Gomes) Barneby \& Grimes. Revista Brasileira de Farmacognosia, v.17, n.2, p. 215219, 2007. Disponível em: <http://www.scielo.br/ scielo.php?script=sci_arttext\&pid=S0102. $695 X 2007000200014 \& \operatorname{lng}=$ en $\&$ nrm=iso $>$. Acesso em: 14 out. 2011. doi: $10.1590 / \mathrm{S} 0102-695 \mathrm{X} 2007000200014$

SEIGLER, D.S. Plant secondary metabolism. Norwell: Kluwer Academic Publishers, 2002. 776p.

SOARES, D.G.S. et al. Avaliação clínica e microbiológica do tratamento da estomatite protética com tintura de Schinus terebinthifolius Raddi (Aroeira). Pesquisa Brasileira em Odontopediatria e Clínica Integrada, v.10, n.3, p.365370, 2010. Disponível em: <http://redalyc.uaemex.mx/redalyc/ pdf/637/63717313006.pdf>. Acesso em: 14 out. 2011. doi: 10.4034/1519.0501.2010.0103.0006.

VASCONCELOS, M.C.A. et al. Avaliação de atividades biológicas das sementes de Stryphmodndron obovatum Benth (Leguminosae). Revista Brasileira de Farmacognosia, v.14, n.1, p.121-127, 2004. Disponível em: <http://dx.doi.org/ 10.1590/S0102-695X2004000200005>. Acesso em: 14 out. 2011. doi: $10.1590 / \mathrm{S} 0102-695 \mathrm{X} 2004000200005$.

VERDI, L.G. et al. Gênero Baccharis (Asteraceae): aspectos químicos, econômicos e biológicos. Química Nova, v.28, p.85-94, 2005. Disponível em: <http://dx.doi.org/10.1590/ S0100-40422005000100017>. Acesso em: 14 out. 2011. doi: 10.1590/S0100-40422005000100017. 